\title{
Fornecimento de medicamentos não registrados na Agência Nacional de Vigilância Sanitária: o discurso de ministros do Supremo Tribunal Federal
}

The supply of medicines not registered in Brazilian Health Regulatory Agency: The discourse of Brazilian Federal Supreme Court's Justices

El suministro de los medicamentos no registrados en la Agencia Nacional de Vigilancia Sanitaria: El discurso de los ministros del Supremo Tribunal Federal

RESUMO. Objetivo: O artigo tem como tema geral apresentar os resultados da análise dos argumentos utilizados pelos Ministros do Supremo Tribunal Federal nas ações judiciais que versam sobre medicamentos não registrados na Agência Nacional de Vigilância Sanitária. Metodologia: Constituiu-se de um estudo de caso com método comparativo entre os votos dos ministros, em que foram apontadas as semelhanças e divergências no julgamento de dois Recursos Extraordinários. Resultados: Verificou-se divergências sobre o tema da dispensação de medicamentos não padronizados pelo SUS. Conclusão: Os ministros consideraram a proteção da saúde da população brasileira em relação aos riscos, ao ressaltarem a importância do registro na Anvisa, pois isso garantiria uma maior confiabilidade.

Palavras-chaves: Judicialização da Saúde. Vigilância Sanitária. Direito à Saúde.

ABSTRACT. Objective: This article presents as a general theme the results of the analysis of arguments of Brazilian Federal Supreme Court's Justices in lawsuits about medicines not registered in Brazilian Health Regulatory Agency. Methodology: It is constituted of a comparative case study of the Justices' votes, in which it is pointed out the similarities and divergences in two extraordinary appeals' judgments. Results: It was found that there were differences on the issue of the dispensation of non-standardized medications by SUS. Conclusion: The Justices considered the protection of Brazilian population health in relation to the risks by highlighting the importance of having the Brazilian Health Regulatory Agency' registration, because that grants better reliability.

Keywords: Judicialization of Health. Health Surveillance. Right to Health.

RESUMEN. Objetivo: El presente articulo tiene como general los resultdos de las análisis de los argumentos utilizados por los Ministros del Supremo Tribunal Federal en las acciones judiciales que tratan sobre medicamentos no registrados en la Agencia Nacional de Vigilancia Sanitaria.Metodología: Se trata de un estudio de caso con metodo comparativo entre los votos de los ministros donde fueron señalados las similitudes y divergencias en el juicio de dos recursos extraordinarios. Resultados: Se ha comprobado que hubo diferencias sobre la cuestión de la dispensa de medicamentos no estandarizados por SUS. Conclusión: Los ministros consideran la proteccion de la salud brasileña en relacion a los riesgos al

\footnotetext{
${ }^{1}$ Universidade de Brasília. E-mail: gessikacavalcante 14@hotmail.com
} 
resaltar la importancia del riesgo en la Anvisa, porque eso garantizaba una mayor confiabilidad.

Palabras-Ilave: Judicialización de la Salud. Vigilância Sanitaria. Derecho a la Salud.

\section{Introdução}

O processo histórico de construção do Sistema Único de Saúde (SUS) envolveu grandes transformações sociais, econômicas e principalmente políticas. Sua criação é "emblemática na construção democrática" (1), e somente foi possível após o reconhecimento do direito à saúde na Constituição Federal de 1988.

Para Delduque et al (2) apesar dessa conquista social, muitos cidadãos, individualmente ou reunidos em grupos de pressão, recorrem ao Poder Judiciário para buscar a efetivação das promessas constitucionais. No entanto, o crescimento desenfreado do número de decisões judiciais relacionadas à saúde se tornou um dos problemas mais tormentosos para a política de saúde brasileira.

Logo, o fenômeno da judicialização da saúde sinaliza que as políticas públicas não estão conseguindo contemplar, de forma universal, integral e igualitária, as necessidades dos cidadãos que, de acordo com o ordenamento jurídico vigente, têm legitimidade para exigir a prestação dos serviços pelo Sistema Único de Saúde.

Uma das matérias mais recorrentes na judicialização da saúde pública tem sido o fornecimento de medicamentos, cuja obrigatoriedade está prevista no artigo 6ำ da Lei no 8.080/90 (3), que dispõe sobre as condições para a promoção, proteção e recuperação da saúde, a organização e o funcionamento dos serviços correspondentes e dá outras providências, sob a denominação de "assistência farmacêutica".

De acordo com o art.16 da Lei n 6360/76 (4), que dispõe sobre a Vigilância Sanitária a que ficam sujeitos os Medicamentos, as Drogas, os Insumos Farmacêuticos e Correlatos, Cosméticos, Saneantes e Outros Produtos, e dá outras Providências, para que um novo medicamento possa ser registrado e disponibilizado no mercado brasileiro, é necessária a comprovação de sua segurança e eficácia no tratamento da doença, o que exige de uma série de procedimentos prévios. Além disso, garante-se, por meio do processo de registro, a regulação econômica do comércio dos medicamentos.

Há muitas críticas à utilização das vias judiciais no acesso aos serviços de saúde, principalmente quando as decisões obrigam o fornecimento de medicamentos sem registro na Agência Nacional de Vigilância Sanitária (Anvisa) ou não incorporados pela Comissão 
Nacional de Incorporação de Tecnologias (CONITEC), pois existe um "planejamento coletivo" que pode ser afetado com uma decisão em nível individual. (2)

Dentre as competências legais atribuídas à Anvisa, está o controle sanitário da produção e comercialização de medicamentos (5). E a CONITEC, por sua vez, é responsável pelas análises sobre a incorporação de tecnologia em saúde no âmbito do SUS. (6)

No ano de 2016, o Supremo Tribunal Federal (STF) interrompeu, pela segunda vez, o julgamento conjunto de dois Recursos Extraordinários (566.471RN e 657.718 MG) que abordavam o fornecimento de remédios de alto custo não disponíveis na lista do SUS e de medicamentos não registrados na Anvisa, sendo este último, o tema escolhido para a elaboração deste trabalho, em razão da grande controvérsia gerada em torno do assunto, mesmo entre os ministros da Corte.

Nesse sentido, o presente estudo teve como objetivos analisar os argumentos utilizados pelos ministros do STF nos Recursos Extraordinários REs 566.471/RN (que trata da dispensação de medicamentos de alto custo não incorporados pelo SUS) e 657.715/MG (que trata da dispensação de medicamentos sem registro na Anvisa), verificando a existência de argumentos semelhantes e/ou divergentes, bem como de argumentos que consideram a proteção da saúde da população como fator determinante para a concessão ou negação de medicamentos, partindo-se da hipótese que a garantia da proteção à saúde foi a principal linha argumentativa dos ministros.

\section{Metodologia}

A pesquisa consistiu em um estudo de caso com método comparativo entre os votos dos três ministros do STF (Ministro Marco Aurélio de Melo, Ministro Luís Roberto Barroso e Ministro Luiz Edson Fachin) a respeito do julgamento de dois Recursos Extraordinários (RE 566.471 e RE657.718) que abordavam o fornecimento de medicamentos de alto custo não disponíveis na lista do SUS e de medicamentos não registrados na Anvisa, respectivamente.

Os votos são de acesso público e estão disponíveis no sítio eletrônico do próprio tribunal.

Segundo Goode e Hatt (7) estudo de caso é um meio de organizar os dados, preservando do objeto estudado o seu caráter unitário, pretendendo investigar, como uma unidade, as características mais importantes. 
Já para Yin (8) o estudo de caso reproduz "uma investigação empírica e compreende um método abrangente, com a lógica do planejamento, da coleta e da análise de dados".

Após coleta e organização dos discursos foram elaborados dois quadros no Microsoft Word 2010, para realizar a análise das decisões dos ministros e para facilitar a verificação de argumentos semelhantes e/ou divergentes através do método comparativo (9) que realiza comparações com o objetivo de verificar semelhanças e explicar divergências. $O$ método comparativo ao (9) "ocupar-se das explicações de fenômenos, permite analisar o dado concreto, deduzindo elementos constantes, abstratos ou gerais nele presentes".

De modo complementar, o trabalho contou com revisão de literatura em livros e artigos científicos e levantamento da legislação vigente.

\section{Resultados e Discussão}

\section{Das teses propostas pelo STF sobre o fornecimento de medicamentos não padronizados pelo SUS}

Os acórdãos escolhidos para o estudo apresentam profunda reflexão sobre o fornecimento, pelo SUS, de medicamentos não incorporados, e porque o próprio STF os reuniu para julgamento conjunto, tendo em vista a similaridade de seu objeto, a repercussão geral do tema e a necessidade de pacificar a matéria.

No quadro 1, buscou-se compilar o trecho mais representativo, que resume de forma mais elementar os votos de cada um dos ministros e, nas seções seguintes, suas razões foram analisadas de forma mais detalhada, de modo a identificar os argumentos a favor e contra o fornecimento desse tipo de fármaco pelo SUS.

Quadro 1: Recursos Extraordinários com os votos dos Ministros do STF, 2016.

\begin{tabular}{|l|l|l|l|}
\hline \multicolumn{3}{|c|}{ Teses propostas nos votos dos Recursos Extraordinários } \\
\hline & № Processo & \multicolumn{1}{|c|}{ Ministro } & \multicolumn{1}{c|}{ Discurso } \\
\hline & & & $\begin{array}{l}\text { "O Estado está obrigado a fornecer } \\
\text { medicamento registrado na Anvisa, como } \\
\text { também o passível de importação, sem similar } \\
\text { nacional, desde que comprovada à } \\
\text { indispensabilidade para a manutenção da } \\
\text { saúde da pessoa, mediante laudo médico, e } \\
\text { tenha registro no país de origem". }\end{array}$ \\
\hline 2 & RE 566.471 RN & $\begin{array}{l}\text { Marco Aurélio } \\
\text { de Melo }\end{array}$ & $\begin{array}{l}\text { "O Estado não pode ser obrigado a fornecer } \\
\text { medicamentos experimentais, sem eficácia e } \\
\text { segurança comprovadas, em nenhuma }\end{array}$ \\
\hline
\end{tabular}




\begin{tabular}{|l|l|l|l|}
\hline & & $\begin{array}{l}\text { hipótese. Já em relação a medicamentos não } \\
\text { registrados na Anvisa, mas com comprovação } \\
\text { de eficácia e segurança, Estado somente } \\
\text { pode ser obrigado a fornecê-los na hipótese } \\
\text { de irrazoável mora da Agência em apreciar o } \\
\text { pedido de registro (prazo superior a 365 dias), } \\
\text { quando preenchidos três requisitos". }\end{array}$ \\
\hline 3 & RE 566.471 RN & $\begin{array}{l}\text { "No âmbito da política de assistência à saúde, } \\
\text { é possível ao Estado prever, como regra geral, } \\
\text { a vedação da dispensação, do pagamento, do } \\
\text { ressarcimento ou do reembolso de } \\
\text { medicamento e produto, nacional ou } \\
\text { importado, sem registro na Agência Nacional } \\
\text { de Vigilância Sanitária (Anvisa)". }\end{array}$ \\
\hline
\end{tabular}

Fonte: Elaborado pela autora com base na análise dos Recursos Extraordinários dos Ministros do Supremo Tribunal Federal.

\section{Ministro Marco Aurélio de Melo}

O ministro Marco Aurélio de Melo argumentou, em seu voto, registrado na sessão do dia 15/09/2016, que existe obrigatoriedade de que o Estado forneça medicamentos, mesmo sem o devido registro na Anvisa, considerando que o indivíduo tem o direito constitucionalmente assegurado à saúde.

Já no aditamento, ele propôs a tese de que medicamentos não registrados no Brasil, mas devidamente testados e certificados no exterior, poderiam ser fornecidos pelo Poder Público. Entretanto, com a ressalva de que o seu provimento deveria ser limitado aos cidadãos que não possuíssem condições financeiras de adquirí-los.

O ministro também apontou, em seu voto, a tese da solidariedade familiar, alegando que o Poder Público poderia exigir a devolução dos valores despendidos com a aquisição desse medicamento, caso fosse descoberto que os familiares do paciente tinham condições financeiras para custeá-lo. Todavia, no aditamento, ele abrandou essa postura, retirando a necessidade de comprovação da hipossuficiência dos familiares, pois bastaria que houvesse falta de espontaneidade dos membros da família solidária em custear o tratamento.

Nesse sentido, ele argumentou (10):

Ausente à espontaneidade do familiar, incumbe ao Estado atuar em nome da coletividade, sem prejuízo dos consectários legais. Descabe, a pretexto de ter-se membro da família com capacidade econômico-financeira de prover certo medicamento, eximir-se pura e simplesmente da obrigação de fornecêlo. (RE 566.471 RN). 
Essa condição que o ministro faz referente à família do paciente é bastante contraditória, pois (11) "argumentar que familiar com posses deve arcar com as despesas do medicamento de um parente seu, cabendo ao Poder Público o direito de regresso, chega a ser absurda".

\section{Ministro Luís Roberto Barroso}

O ministro Luís Roberto Barroso, por sua vez, alegou que não existe obrigatoriedade de a Administração Pública conceder medicamentos não registrados na Anvisa. Para embasar seu posicionamento, o magistrado se apoiou na teoria dos recursos limitados.

O ministro ainda ponderou a inadequação da judicialização das políticas voltadas para a saúde, pois, em seu entendimento, isso traria prejuízos para a organização administrativa, ineficiência na aplicabilidade das receitas públicas e ainda uma seletividade na prestação da saúde, já que o indivíduo que recorre à Justiça acaba sendo beneficiado, em detrimento da coletividade.

O julgador fez suas observações em relação à situação em que o medicamento é realmente considerado experimental, e também a hipótese em que a eficácia e a segurança do medicamento já tiverem sido comprovadas e os testes concluídos.

No primeiro caso (medicamentos experimentais), ele concluiu que o Poder Judiciário não pode obrigar o Estado a fornecer remédios sem comprovação científica de eficácia e segurança, e que ainda estejam em fase de pesquisas e testes, sem a confirmação de seus efeitos. Porém, na segunda hipótese, o ministro afirmou que o fornecimento pode ser concedido, em casos excepcionais, quando envolver medicamento cujo pedido de solicitação de registro na Anvisa estiver aguardando conclusão por prazo superior a 365 dias e, cumulativamente, forem preenchidos os seguintes requisitos:

i. A existência de pedido de registro do medicamento no Brasil;

ii. A existência de registro do medicamento pleiteado em renomadas agências de regulação no exterior: (EUA, União Europeia e Japão);

iii. A inexistência de substituto terapêutico registrado na Anvisa.

Em regra, portanto, o voto do ministro Luís Riberto Barroso apontou para o indeferimento em relação ao fornecimento, pelo Estado, de medicamentos não registrados na Anvisa, alegando que esse registro garantiria a proteção à saúde pública, à medida que 
atesta a eficácia, segurança e qualidade dos fármacos comercializados no país, bem como o devido controle de preços.

Desse discurso, vale destacar a ênfase dada à necessidade de um diálogo entre o Judiciário e os órgãos técnicos, como a CONITEC, para avaliação dos requisitos de dispensação de medicamentos e da possibilidade ou não de incorporação de determinado fármaco, pelo SUS.

\section{Luiz Edson Fachin}

Em seu voto, o ministro Edson Fachin anuiu com o deferimento, pelo Poder Judiciário, em relação à dispensação de medicamentos que não padronizados pelo SUS, mesmo nos casos de ausência de registro na Anvisa. Para isso, segundo ele, seria necessário o atendimento a cinco parâmetros probatórios, sendo dois deles distintos em relação ao voto do ministro Luís Roberto Barroso.

Os parâmetros são:

i. Demonstração de prévio requerimento administrativo junto à rede pública;

ii. Preferencial prescrição por médico ligado à rede pública;

iii. Preferencial designação do medicamento pela Denominação comum Brasileira (DCB) e, em não havendo a CDB, a Denominação Comum internacional (DCI);

iv. Justificativa da inadequação ou da inexistência de medicamento/tratamento dispensado na rede pública;

v. Em caso de negativa de dispensa na rede pública, é necessária a realização de laudo médico indicando a necessidade do tratamento, seus efeitos, estudos da Medicina Baseada em Evidências (BEM) e vantagens para o paciente, além e comparar com eventuais fármacos fornecidos pelo SUS.

O ministro propõe, como regra geral, a vedação da dispensação, do pagamento, do ressarcimento ou do reembolso de medicamento e produto, nacional ou importado, sem registro na Anvisa, mas concorda que, em situações excepcionais, o caso seja ajuizado, preferencialmente em ações coletivas, mediante ampla produção de provas.

O julgamento dos dois Recursos Extraordinários aqui analisados, os quais foram reunidos pelo STF, está suspenso desde o voto do ministro Luiz Edson Fachin, pois o ministro Teori Zavascki pedira vista do processo, por se tratar de um caso complexo. 
A complexidade do tema é confirmada quando se examina a diversidade de argumentos, por vezes divergentes, utilizados nos votos, inclusive a total reforma do voto do mesmo ministro Marco Aurélio de Mello, por aditivo.

Para melhor ilustração e comparação dos argumentos-chave dos discursos de cada um deles, elaborou-se o quadro 2.

Quadro 2: Argumentos-chave dos discursos dos Ministros do STF, 2016.

\begin{tabular}{|c|c|c|c|}
\hline Tópicos & $\begin{array}{l}\text { Ministro Marco Aurélio de } \\
\text { Mello }\end{array}$ & $\begin{array}{c}\text { Ministro Luís Roberto } \\
\text { Barroso }\end{array}$ & Ministro Edson Fachin \\
\hline $\begin{array}{l}\text { O direito à saúde e } \\
\text { o orçamento }\end{array}$ & $\begin{array}{l}\text { Problemas orçamentários } \\
\text { não podem ser obstáculos } \\
\text { para a garantia de direitos } \\
\text { previstos } \\
\text { constitucionalmente. }\end{array}$ & $\begin{array}{l}\text { O sistema não seria } \\
\text { sustentável se todos os } \\
\text { remédios, } \\
\text { independentemente de } \\
\text { seu custo e impacto } \\
\text { financeiro, fossem } \\
\text { oferecidos pelo Estado a } \\
\text { todas as pessoas. Cada } \\
\text { cidadão faz jus ao máximo } \\
\text { de justiça em matéria de } \\
\text { saúde que o país possa } \\
\text { pagar. O orçamento é o } \\
\text { locus da discussão. }\end{array}$ & $\begin{array}{l}\text { O sistema deveria } \\
\text { buscar a promoção da } \\
\text { saúde } \\
\text { medicamentos } \\
\text { universalizáveis, ou } \\
\text { seja, que pudessem ser } \\
\text { estendidos a todos que } \\
\text { deles necessitassem, } \\
\text { do ponto de vista } \\
\text { prático e financeiro. A } \\
\text { interferência judicial } \\
\text { pode interferir no } \\
\text { deslocamento de } \\
\text { recursos de outra área } \\
\text { da saúde, por isso deve } \\
\text { haver critérios para as } \\
\text { determinações } \\
\text { obrigatoriedade. }\end{array}$ \\
\hline $\begin{array}{l}\text { O direito à saúde e } \\
\text { o papel do Estado }\end{array}$ & $\begin{array}{l}\text { O Estado deve tutelar o } \\
\text { mínimo existencial (inclui a } \\
\text { saúde). }\end{array}$ & $\begin{array}{lr}\text { O Estado tem a obrigação } \\
\text { de fornecer } \quad \text { os } \\
\text { medicamentos } \\
\text { incorporados na política } \\
\text { pública de saúde }\end{array}$ & $\begin{array}{lr}\text { É dever do } & \text { Estado } \\
\text { promover a saúde de } \\
\text { todos, } & \text { conforme } \\
\text { assegurado } & \text { na } \\
\text { Constituição } & \end{array}$ \\
\hline $\begin{array}{l}\text { Regra geral sobre o } \\
\text { direito de acesso a } \\
\text { medicamentos }\end{array}$ & $\begin{array}{l}\text { O direito à saúde é direito } \\
\text { social fundamental e engloba } \\
\text { o acesso a medicamentos }\end{array}$ & $\begin{array}{l}\text { Infere-se que o } \\
\text { saúde é relativo - } \\
\text { da dependo à } \\
\text { preestabelecida, } \\
\text { regra geral }\end{array}$ & $\begin{array}{l}\text { Há direito subjetivo às } \\
\text { políticas públicas de } \\
\text { assistência à saúde - } \\
\text { obtenção de } \\
\text { medicamento já } \\
\text { incorporado nas listas } \\
\text { oficiais. Esse direito, no } \\
\text { entanto, está vinculado } \\
\text { aos princípios da } \\
\text { universalidade, } \\
\text { equidade e precaução } \\
\text { ou segurança }\end{array}$ \\
\hline $\begin{array}{l}\text { O direito à saúde a } \\
\text { as políticas de } \\
\text { saúde }\end{array}$ & $\begin{array}{l}\text { Omissões ou falhas na } \\
\text { execução das políticas não } \\
\text { podem obstaculizar o direito à } \\
\text { saúde. }\end{array}$ & $\begin{array}{l}\text { A palavra final, em regra, } \\
\text { sobre a incorporação de } \\
\text { medicamentos, é do Poder } \\
\text { Executivo, e deve ser } \\
\text { aprimorado o diálogo } \\
\text { interinstitucional entre } 0 \\
\text { Judiciário }\end{array}$ & $\begin{array}{l}\text { O Judiciário não é } \\
\text { responsável pelas } \\
\text { escolhas políticas, e } \\
\text { deve agir de forma } \\
\text { parcimoniosa em } \\
\text { situações que possam } \\
\text { afetar a alocação de }\end{array}$ \\
\hline
\end{tabular}




\begin{tabular}{|c|c|c|c|}
\hline & & $\begin{array}{l}\text { atores/entidades que } \\
\text { possuam conhecimento } \\
\text { técnico }\end{array}$ & $\begin{array}{l}\text { recursos públicos }- \\
\text { acredita na importância } \\
\text { de definição de critérios } \\
\text { claros para os } \\
\text { julgamentos futuros }\end{array}$ \\
\hline $\begin{array}{l}\text { Os limites da } \\
\text { atuação judicial } \\
\text { acerca da matéria }\end{array}$ & $\begin{array}{l}\text { A intervenção judicial deveria } \\
\text { ser adotada em situações } \\
\text { concretas, não alcançadas } \\
\text { pelas políticas públicas } \\
\text { vigentes. }\end{array}$ & $\begin{array}{l}\text { A atuação do Judiciário } \\
\text { deveria se restringir aos } \\
\text { casos de não- } \\
\text { fornecimento } \\
\text { medicamentos de } \\
\text { padronizados pelo suS. } \\
\mathrm{Na} \text { hipótese de o } \\
\text { medicamento não ser } \\
\text { incorporado pelo SUS, o } \\
\text { Judiciário somente poderia } \\
\text { determinar o seu } \\
\text { fornecimento em casos } \\
\text { excepcionais. A atuação } \\
\text { do Judiciário sem critérios } \\
\text { pode desorganizar a } \\
\text { atividade administrativa. }\end{array}$ & $\begin{array}{l}\text { A tutela jurisdicional } \\
\text { deve ser, } \\
\text { preferencialmente, } \\
\text { pleiteada em ações } \\
\text { coletivas ou } \\
\text { coletivizáveis. } \mathrm{Na} \\
\text { hipótese de o } \\
\text { medicamento não ser } \\
\text { incorporado pelo SUS, } \\
\text { o Judiciário somente } \\
\text { poderia determinar o } \\
\text { seu fornecimento em } \\
\text { casos excepcionais. }\end{array}$ \\
\hline $\begin{array}{l}\text { Requisitos para a } \\
\text { obrigatoriedade de } \\
\text { fornecimento de } \\
\text { medicamentos não } \\
\text { incorporados }\end{array}$ & $\begin{array}{lr}\text { Comprovação } & \text { da } \\
\text { imprescindibilidade } & \text { do } \\
\text { tratamento e da incapacidade } \\
\text { financeira da aquisição. }\end{array}$ & $\begin{array}{l}\text { Possível somente após a } \\
\text { demonstração da eficácia } \\
\text { e da segurança do } \\
\text { fármaco, quando o prazo } \\
\text { de registro na Anvisa } \\
\text { ultrapassar } 365 \text { dias, } \\
\text { sendo necessária a } \\
\text { comprovação dos } \\
\text { seguintes requisitos: } \\
\text { existência de pedido de } \\
\text { registro do medicamento } \\
\text { no Brasil; existência de } \\
\text { registro do medicamento } \\
\text { pleiteado em renomadas } \\
\text { agências de regulação no } \\
\text { exterior; inexistência de } \\
\text { substituto terapêutico } \\
\text { registrado na Anvisa. }\end{array}$ & 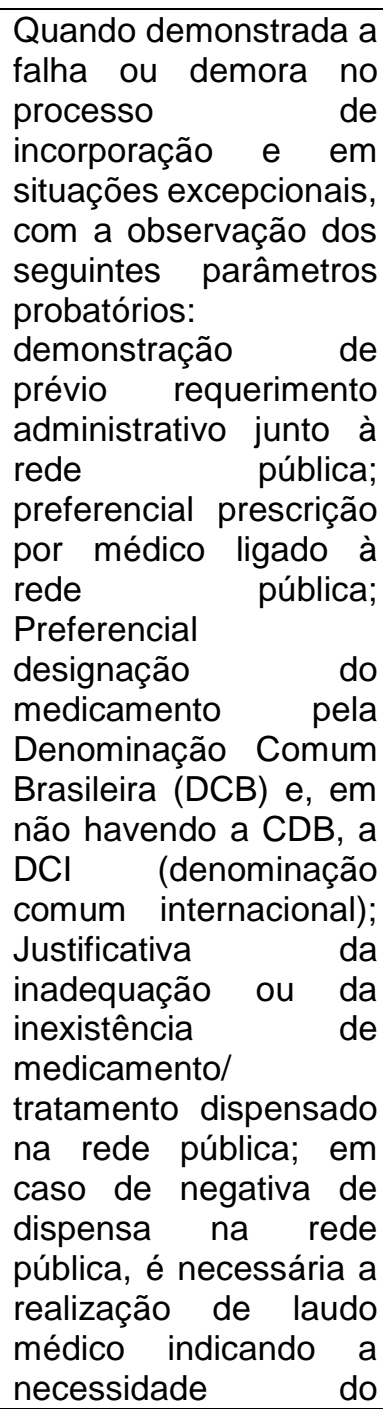 \\
\hline
\end{tabular}




\begin{tabular}{|c|c|c|c|}
\hline & & & $\begin{array}{l}\text { tratamento, seus } \\
\text { efeitos, estudos da } \\
\text { Medicina Baseada em } \\
\text { Evidências - MBE e } \\
\text { vantagens para o } \\
\text { paciente, além de } \\
\text { comparar r com } \\
\text { eventuais fármacos } \\
\text { fornecidos pelo SUS }\end{array}$ \\
\hline $\begin{array}{lr}\text { Sobre } & a \\
\text { hipossuficiência } & \text { do } \\
\text { requente e } & \text { da } \\
\text { família } & \end{array}$ & $\begin{array}{l}\text { O dever dos membros da } \\
\text { família para com o paciente } \\
\text { (solidariedade familiar) - a } \\
\text { manifestação espontânea. }\end{array}$ & $\begin{array}{l}\text { Não inclui no discurso o } \\
\text { princípio da solidariedade } \\
\text { familiar. Na hipótese de } \\
\text { mora injustificada da } \\
\text { Anvisa, prevê que a } \\
\text { garantia de acesso ao } \\
\text { medicamento, pelo SUS, } \\
\text { depende da comprovação } \\
\text { da hipossuficiência do } \\
\text { paciente }\end{array}$ & $\begin{array}{l}\text { Não inclui no discurso } \\
\text { da hipossuficiência } \\
\text { nem da solidariedade } \\
\text { familiar }\end{array}$ \\
\hline
\end{tabular}

Fonte: Elaborado pela autora com base na análise dos Recursos Extraordinários dos Ministros do Supremo Tribunal Federal.

A análise comparativa das linhas argumentativas dos três ministros que votaram sobre a matéria evidenciou que: a postura do Ministro Marco Aurélio de Mello foi mais prócidadão, ignorando aspectos orçamentários e refutando a alegação sobre a reserva do possível.

A reserva do possível (12) foi "uma prática jurídica alemã importada e perfeitamente adequada à realidade brasileira a partir da década de 1990, sendo invocada como um limite fático e intransponível diante de uma alegada escassez de recursos".

O ministro Luis Alberto Barroso apresentou um discurso mais afinado com a Administração Pública, baseado na teoria da reserva do possível, da limitação de recursos orçamentários, e da necessidade de se respeitar a política estabelecida previamente e as competências dos órgãos técnicos.

Por fim, o discurso do ministro Luiz Edson Fachin se aproximou do posicionamento do ministro Barroso, no sentido de julgarem necessário o estabelecimento de critérios claros para a apreciação das demandas, e do caráter excepcional da obrigação de fornecimento de fármacos não padronizados. 


\section{Considerações Finais}

Diante das divergências encontradas nos votos dos componentes do STF sobre o tema da dispensação de medicamentos não padronizados pelo SUS, espera-se que a decisão final realmente contemple os princípios doutrinários do SUS, quais sejam universalidade, integralidade e equidade.

Percebe-se que os argumentos utilizados pelos ministros consideraram a proteção da saúde da população brasileira em relação aos riscos, ao enfatizarem a importância do registro na Anvisa ou na agência específica do país de origem do medicamento, pois isso garantiria uma maior confiabilidade.

Os argumentos utilizados também dão conta de que o direito a saúde é um direito fundamental. Todavia, um dos votos põe mais ênfase na discussão sobre os recursos limitados e sobre a necessidade de a Administração Pública ter seu orçamento equilibrado, por meio da busca da melhor forma de atender as demandas em saúde com menor custo possível e a maior efetividade.

A discussão sobre a solicitação de medicamentos não registrados na Anvisa, que resultou em disparidades nas decisões dos ministros, ainda terá novos desmembramentos, logo, sugere-se o desenvolvimento de novos estudos sobre o tema, visando o acompanhamento dos trâmites e o aprofundamento da análise.

\section{Referências}

1. Alves SMC, Delduque MC, Neto ND. Direito Sanitário em Perspectiva. Volume 2. Brasília: ESMPU: Fiocruz; 2013.

2. Delduque MC, Badim S, Ciarlini AL. Judicialização das políticas de saúde no Brasil (pág. 181-217). In: Alves SMC, Delduque MC, Neto ND. Direito Sanitário em Perspectiva. Volume 2. Brasília: ESMPU: Fiocruz; 2013.

3. Brasil. Lei Federal $n^{\circ}$ 8.080, de 19 de setembro de 1990. Dispõe sobre as condições para promoção, proteção e recuperação da saúde, a organização e o funcionamento dos serviços correspondentes e dá outras providências. Disponível em: http://www.planalto.gov.br/ccivil 03/leis/L8080.htm [Acesso em 27.jul.2017].

4. Brasil. Lei Federal no 6.360, de 23 de setembro de 1976. Dispõe sobre a Vigilância Sanitária a que ficam sujeitos os Medicamentos, as Drogas, os Insumos Farmacêuticos e Correlatos, Cosméticos, Saneantes e Outros Produtos, e dá outras Providências.

Disponível em: 
http://www.aeap.org.br/doc/lei federal 6360 de 23 de setembro de 1976.pdf [Acesso em 29.jul.2017].

5. Brasil. Lei Federal no 9.782, de 26 de janeiro de 1999. Define o Sistema Nacional de Vigilância Sanitária, cria a Agência Nacional de Vigilância Sanitária, e dá outras providências. Disponível em http://www.camara.gov.br/sileg/integras/522754.pdf [Acesso em 29.jul.2017].

$6 \quad$ Brasil. Lei Federal 12.401, de 28 de abril de 2011. Altera a Lei no 8.080, de 19 de setembro de 1990, para dispor sobre a assistência terapêutica e a incorporação de tecnologia em saúde no âmbito do Sistema Único de Saúde - SUS. Disponível em: http://www.planalto.gov.br/ccivil 03/ ato2011-2014/2011/lei/l12401.htm [Acesso em 29.jul.2017].

7. Goode WJ, Hatt PK. Métodos em pesquisa social. São Paulo: Companhia Editora Nacional; 1979.

8. Yin R. Estudo de caso: planejamento e métodos. Porto Alegre: Bookman; 2001.

9. Prodanov CC, Freitas E. Metodologia do Trabalho Científico: métodos e técnicas de pesquisa e do trabalho acadêmico. Novo Hamburgo: Feevale; 2013.

10. Supremo Tribunal Federal. Recursos Extraordinários. Disponível em: http://www.stf.jus.br/portal/pesquisa/listarPesquisa.asp?termo=Recursos+Extraordin\%E1 rio s\&consultaPesquisaAvisos [Acesso em 28.jul.2017].

11. Santos L. Decisão parcial do STF quanto ao fornecimento de medicamento de alto custo sem registro no País. Direito do Estado. 07 out 2016 Disponível em:

http://www.direitodoestado.com.br/colunistas/lenir-santos/decisao-parcial-do-stf-quanto-aofornecimento-de-medicamento-de-alto-custo-sem-registro-no-pais [Acesso em 10.out.2017]

12. Mazza F. Judicialização da saúde e planejamento orçamentário: as decisões do Supremo Tribunal Federal. In: Santos L, Terrazas F. Judicialização da Saúde no Brasil. Campinas: Saberes; 2014.

\section{Como citar este artigo:}

Cavalcante G. Fornecimento de medicamentos não registrados na Agência Nacional de Vigilância Sanitária: o discurso de ministros do Supremo Tribunal Federal. Revista Cadernos Ibero-Americanos de Direito Sanitário. 2018 jan./mar, 7(1):203-214. 